\title{
Dinâmica da resistência à penetração de um Latossolo Vermelho da Microrregião de Goiânia, GO
}

\author{
Geraldo C. Oliveira ${ }^{1}$, Eduardo C. Severiano ${ }^{1} \&$ Carlos R. Mello ${ }^{2}$
}

\begin{abstract}
RESUMO
O objetivo principal deste estudo é avaliar o efeito da umidade e da densidade do solo na dinâmica da resistência à penetração de um Latossolo Vermelho da Microrregião de Goiânia, GO. Foram amostradas: área sob pastejo rotacionado, na 1) Touceira e 2) Entre touceira; 3) Barreirão (área de renovação de pastagem); 4) Área sob Pivô Central; 5) Área sob Plantio Direto; 6) Mata. Realizaram-se, em cada área, testes de penetrometria em três diferentes teores de umidade no solo e se coletaram seis amostras não deformadas, nas profundidades de 0-5 e 20-30 cm em anéis volumétricos, para determinação da densidade do solo, capacidade de campo, volume total de poros, microporosidade e macroporosidade do solo. Os tratamentos afetaram, de forma diferenciada todos os atributos analisados; pelo teste de penetrometria, 0 diagnóstico mostrou-se eficiente quando acompanhado da análise de densidade do solo e da umidade; o Latossolo em estudo deve oferecer alguma restrição ao desenvolvimento das plantas cultivadas nas áreas sob pivô central e pastejo rotacionado, quando o solo se encontrar em baixas condições de umidade.
\end{abstract}

Palavras-chave: resistência do solo, degradação estrutural, manejo de solos do cerrado, água no solo

\section{Penetration resistance dynamics of a Dark Red Latosol of Microregion of Goiania, State of Goias, Brazil}

\begin{abstract}
This study aims to evaluate soil moisture and bulk density effects on penetration resistance dynamics of Dark Red Latosol, located in the Microregion of Goiânia, Goias. Area under rotating pasture were sampled 1) in lines and 2) between lines; 3) pasture renewal area; 4) area under Central Pivot; 5) area under no-tillage and 6) forest. Penetrometry tests were done for three different soil moistures, and six undisturbed soil samples were collected in layers of 0-5 and 20-30 cm for determination of bulk density, soil moisture at field capacity, total porosity, and micro and macro-porosity. Soil use and management affected in a differentiated way, all analyzed soil attributes; penetrometry diagnosis test was efficient when accompanied by bulk density and soil moisture analysis; the Dark Red Latosol studied appears to offer a restriction on types of crops cultivated in areas under central pivot and in rotating pasture when soil presents low moisture.
\end{abstract}

Key words: soil resistance, structural degradation, cerrado soil management, soil moisture 


\section{INTRODUÇÃO}

O Campus II da Universidade Federal de Goiás, localizado em Goiânia, GO, é predominantemente recoberto por Latossolos Vermelhos (Lopes et al., 1997), o que torna esta área representativa de toda a região Sul do Estado de Goiás (SEPLAN/AGIM, 2002).

Nesta região é forte a tradição para a pecuária extensiva. Nos últimos anos, entretanto, em função da excelência em fertilidade física dos seus solos e relevo, principalmente, ela vem experimentando fortes mudanças para o uso intensivo do solo na pecuária e agricultura, muitas das vezes irrigadas (Sano et al., 2004) carecendo, portanto, de estudos diagnósticos da qualidade estrutural dos solos, haja vista a potencialidade de compactação nessas condições de manejo (Imhoff et al., 2000; Oliveira et al., 2003).

Em áreas irrigadas e visando ao maior número possível de safras, os produtores analisam, por ocasião do manejo, apenas o aspecto visual da camada superficial do solo, quase sempre desrespeitando as condições ideais de umidade do solo (Oliveira et al., 2003), o que pode levar a alteração na porosidade do solo, com conseqüências na resistência à penetração, armazenamento de água e disponibilidade de nutrientes para as plantas (Camargo \& Alleoni, 1997), colocando em risco a sustentabilidade ambiental.

Entre os fatores que influenciam os atributos físicos de um solo sob pastagem, Imhoff et al. (2000) destacam a taxa de lotação empregada e a umidade do solo no momento do pastejo, em concordância com Phene \& Beale (1972) que enfatizam a importância do controle da umidade do solo, como prática de manejo.

A resistência do solo à penetração é um índice integrado pela densidade do solo, textura, matéria orgânica e umidade do solo (Camargo \& Alleoni, 1997; Imhoff et al., 2000; Tormena et al., 2004; Ribon \& Tavares Filho, 2004); sendo assim e apesar da facilidade de trabalho com este equipamento, a validação dos resultados obtidos com o mesmo depende, além do seu uso correto (Camargo \& Alleoni, 1997; Torres \& Saraiva, 2001), da caracterização do solo estudado. Apesar disto, em muitos dos trabalhos desenvolvidos em solos da região de Goiânia envolvendo esta ferramenta, não se tem levado em consideração esses fatores; na maioria das vezes, o solo não tem sido caracterizado adequadamente e não se tem quantificado umidade do solo no momento do diagnóstico; exemplos disto são os estudos de Teixeira Neto (2002) que trabalhou na mesma unidade de solo deste estudo, e de Magalhães et al. (2001) que lidaram com Latossolos do entorno de Goiânia; na metodologia desses trabalhos só foram destacadas a classe de solo e a época do ano em que foram realizados os testes de penetrometria.

O presente trabalho objetiva avaliar a eficiência do diagnóstico da estrutura do solo pelo teste de resistência do solo à penetração, em função da umidade e densidade do solo, em um Latossolo Vermelho argiloso da microrregião de Goiânia, GO, submetido a diferentes práticas de uso e manejo.

\section{MATERIAL E MÉTODOS}

O trabalho foi desenvolvido em áreas experimentais localizadas no Campus II da Universidade Federal de Goiás, Goiânia, GO, latitude $16^{\circ} 35^{\prime} 12^{\prime}$ S, longitude 49²1' 14” WGr, a $730 \mathrm{~m}$ de altitude. O clima local é do tipo Aw, segundo Köppen, clima quente e úmido, com longa estação seca e precipitações anuais médias de $1600 \mathrm{~mm}$.

Na condução deste estudo selecionaram-se áreas experimentais em solo classificado como Latossolo Vermelho argiloso caulinítico - oxídico (EMBRAPA, 1999) consistindo nos seguintes tratamentos: Uma área de pastagem irrigada, cultivada com capim Tanzânia (Panicum maximum), explorada na forma de pastejo rotacionado com número médio de 5-6 Unidade Animal ha-1 no período chuvoso, e 2-3 Unidade Animal ha-1 no período seco, avaliando-se: 1) área de influência da touceira do capim (Touceira) e 2) área entre as touceiras do capim (Entre touceiras); 3) área experimental de renovação de pastagem pelo Sistema Barreirão (Barreirão) (Kluthcouski et al., 1991); 4) área experimental sob pivô central, submetida a intensa mecanização e ao preparo convencional do solo (Pivô); 5) área experimental sob plantio direto (PD) e 6) área sob vegetação natural (Mata), utilizada como referência.

Realizaram-se, em cada área analisada testes de penetrometria, de forma aleatória (Centeno, 2001), totalizando seis repetições, em setembro/2002, novembro/2002 e janeiro/ 2003, cujo solo se encontrava em três diferentes teores de umidade utilizando-se um penetrômetro de impacto - modelo IAA/Planalsucar; a massa de impacto de quatro quilos sofreu uma queda livre de $40 \mathrm{~cm}$ (Stolf et al., 1983).

Os resultados obtidos em impactos $\mathrm{dm}^{-1}$ foram convertidos para resistência do solo a penetração (RP), através da equação (Stolf et al., 1991):

$$
\operatorname{RP}\left(\mathrm{kgf} \mathrm{cm}^{-2}\right)=5,6+6,89 \mathrm{~N}\left(\text { impactos } \mathrm{dm}^{-1}\right) \text {; }
$$

Para conversão da RP em kgf $\mathrm{cm}^{-2}$ para MPa, multiplicou-se o resultado obtido pela Eq. 1 pela constante 0,098.

Nas duas camadas consideradas contrastantes pelo teste de penetrometria $(0-5 \mathrm{~cm}$ e $20-30 \mathrm{~cm})$, coletaram-se seis amostras deformadas e seis não deformadas, em anéis com capacidade para $80 \mathrm{~cm}^{3}$, por tratamento, para determinação físicohídrica do solo. As amostras não deformadas foram saturadas em bandejas de plástico com água destilada, na altura de mais ou menos $3 / 4$ do cilindro, após preenchimento dos poros por capilaridade, pelo tempo de $24 \mathrm{~h}$; posteriormente, essas amostras foram submetidas a tensão de $6 \mathrm{kPa}$ para determinação da microporosidade e capacidade de campo do solo (Oliveira, 1968; Oliveira et al., 2003) e secadas em estufa a $105^{\circ} \mathrm{C}$ para determinação da densidade do solo (Ds).

O volume total de poros (VTP) foi calculado pela expressão:

$$
\mathrm{VTP}=1-(\mathrm{Ds} / \mathrm{Dp})
$$

sendo Ds, densidade do solo e Dp, densidade de partículas (3 repetições por tratamento e profundidade em amostras 
deformadas, segundo EMBRAPA (1997); a macroporosidade foi determinada pela diferença entre VTP e a microporosidade.

As amostras deformadas foram submetidas a câmaras de Richards, após saturação prévia, na tensão de água correspondente a $1.500 \mathrm{kPa}$ para determinação do ponto de murcha permanente (EMBRAPA, 1997).

Coletaram-se no horizonte diagnóstico do solo (Bw) amostras deformadas para realização de análise granulométrica pelo método da pipeta e dos óxidos pelo ataque sulfúrico (EMBRAPA, 1997), objetivando-se a caracterização do solo; os resultados são apresentados na Tabela 1.

Tabela 1. Caracterização do Latossolo Vermelho da Microrregião de Goiânia, GO ${ }^{(1)}$

\begin{tabular}{|c|c|c|c|c|c|c|c|c|}
\hline \multirow[b]{2}{*}{ Horizonte } & \multicolumn{3}{|c|}{ Ataque Sulfúrico } & \multicolumn{3}{|c|}{ Granulometria } & \multirow{3}{*}{ Ki } & \multirow{3}{*}{$\mathrm{Kr}$} \\
\hline & $\mathrm{SiO}_{2}$ & $\mathrm{Al}_{2} \mathrm{O}_{3}$ & $\mathrm{Fe}_{2} \mathrm{O}_{3}$ & Argila & Silte & Areia & & \\
\hline \multicolumn{7}{|c|}{$\left(g^{~ k g-1}\right)$} & & \\
\hline Bw & 231 & 96 & 126 & 420 & 180 & 500 & 0,79 & 0,60 \\
\hline
\end{tabular}

(1) Amostras retiradas da profundidade entre $56-176 \mathrm{~cm}$; Ki: relação molecular $\mathrm{SiO}_{2} / \mathrm{Al}_{2} \mathrm{O}_{3}$; $\mathrm{Kr}$ : relação molecular $\mathrm{SiO}_{2} /\left(\mathrm{Al}_{2} \mathrm{O}_{3}+\mathrm{Fe}_{2} \mathrm{O}_{3}\right)$ segundo (EMBRAPA, 1999)

Os resultados das análises físico-hídricas e da resistência à penetração em função da umidade do solo, foram submetidos a análise de variância, segundo o delineamento inteiramente casualizado, e a comparação das médias dos tratamentos, pelo teste Tukey, a 5\% de probabilidade.

As curvas de resistência à penetração, em função da densidade do solo, foram obtidas ajustando-se a densidade do solo $\left(\mathrm{kg} \mathrm{dm}^{-3}\right)$ no eixo das abscissas e a resistência à penetração (MPa), no eixo das ordenadas, utilizando-se os dados médios de todos os tratamentos, em um mesmo intervalo de umidade.

\section{RESULTADOS E DISCUSSÃO}

A camada superficial do solo sob pastejo rotacionado, na área sob influência das entre touceiras do Capim Tanzânia (Entre touceiras), apresentou a maior resistência à penetração (RP) dentre todos os tratamentos (Tabela 2), com valores variando de 10,69 $\mathrm{MPa}$, para a umidade do solo $(\theta)$ de $0,29 \mathrm{dm}^{3} \mathrm{dm}^{-3}$ em setembro/2002 (próximo do Ponto de Murcha Permanente, Tabela 3) para 2,46 MPa quando a umidade do solo atingiu $0,46 \mathrm{dm}^{3} \mathrm{dm}^{-3}$, em janeiro/2003 (acima da Capacidade de Campo, Tabela 3); resistência reduzida em 335\%, o que demonstra a importância de se realizar esta avaliação em diferentes umidades do solo, em concordância com Torres \& Saraiva (2001).

Nesta mesma profundidade, a área sob mata ofereceu a menor resistência à penetração quando comparada a outros tratamentos, com valores de RP de 1,28 em setembro/2002, mesmo estando o solo com o menor teor de umidade em relação aos demais tratamentos e com variação de apenas 19,6\% para os valores de resistência entre o maior e o menor teor de umidade estudados no solo (Tabela 2 e Tabela 3), refletindo o estado de preservação da estrutura do solo sob condições naturais.
Tabela 2. Distribuição temporal da resistência do solo à penetração (RP) - MPa e da umidade do solo $(\theta)-d m^{3} d m^{-3}$ em três épocas e duas profundidades de amostragem, do Latossolo Vermelho da Microrregião de Goiânia, GO(1)

\begin{tabular}{|c|c|c|c|c|c|c|}
\hline \multirow{2}{*}{ Uso } & \multicolumn{2}{|c|}{ Setembro/2002 } & \multicolumn{2}{|c|}{ Novembro/2002 } & \multicolumn{2}{|c|}{ Janeiro/2003 } \\
\hline & $\theta$ & RP & $\theta$ & $\mathrm{RP}$ & $\theta$ & RP \\
\hline \multicolumn{7}{|c|}{ Profundidade de $0-5 \mathrm{~cm}$} \\
\hline Mata & 0,18 D & $1,28 \mathrm{Cd}$ & $0,31 \mathrm{~B}$ & $1,22 \mathrm{Cd}$ & $0,39 \mathrm{BC}$ & $1,07 \mathrm{Bd}$ \\
\hline Barreirão & $0,24 \mathrm{BC}$ & 2,20 Cd & $0,32 A B$ & $1,40 \mathrm{Cd}$ & $0,38 \mathrm{BC}$ & $1,22 \mathrm{Bd}$ \\
\hline PD & $0,23 \mathrm{BC}$ & $5,39 \mathrm{BCb}$ & $0,32 A B$ & $1,90 \mathrm{BCd}$ & $0,40 \mathrm{~B}$ & $1,21 \mathrm{Bd}$ \\
\hline Touceira & $0,28 \mathrm{~A}$ & $5,34 \mathrm{BCb}$ & $0,35 A B$ & 2,73 BCcd & $0,43 \mathrm{AB}$ & $1,31 \mathrm{Bd}$ \\
\hline Entre touceiras & $0,29 \mathrm{~A}$ & $10,69 \mathrm{Aa}$ & $0,34 \mathrm{AB}$ & $6,27 \mathrm{Ab}$ & $0,46 \mathrm{~A}$ & 2,46 Acd \\
\hline Pivô & $0,22 \mathrm{C}$ & $6,18 \mathrm{Bb}$ & $0,24 \mathrm{C}$ & $3,63 \mathrm{Bc}$ & $0,33 \mathrm{C}$ & $1,15 \mathrm{Bd}$ \\
\hline \multicolumn{7}{|c|}{ Profundidade de $20-30 \mathrm{~cm}$} \\
\hline Mata & $0,21 \mathrm{C}$ & 2,49 Cc & $0,28 \mathrm{~B}$ & $2,03 \mathrm{BCC}$ & $0,44 \mathrm{AB}$ & $1,36 \mathrm{Bc}$ \\
\hline Barreirão & $0,21 \mathrm{C}$ & $4,54 \mathrm{BCb}$ & $0,27 \mathrm{~B}$ & $2,18 \mathrm{BCC}$ & $0,34 \mathrm{C}$ & $1,79 \mathrm{Abc}$ \\
\hline PD & $0,21 \mathrm{C}$ & $6,74 \mathrm{Ba}$ & $0,30 \mathrm{~B}$ & $2,52 \mathrm{BCc}$ & $0,37 \mathrm{BC}$ & $1,70 \mathrm{Bc}$ \\
\hline Touceira & $0,24 \mathrm{BC}$ & 7,07 Ba & $0,31 \mathrm{~B}$ & 2,63 BCbc & $0,37 \mathrm{BC}$ & $1,70 \mathrm{Bc}$ \\
\hline Entre touceiras & $0,26 \mathrm{BC}$ & 8,54 Aba & $0,32 \mathrm{~A}$ & 2,63 BCbc & $0,37 \mathrm{BC}$ & $1,74 \mathrm{Abc}$ \\
\hline Pivô & $0,23 \mathrm{C}$ & 7,97 Aba & $0,28 \mathrm{~b}$ & 3,43 BCbc & $0,33 \mathrm{C}$ & $2,32 \mathrm{Abc}$ \\
\hline
\end{tabular}

(1) Para cada época e independente da profundidade, médias seguidas das mesmas letras maiúsculas nas colunas, não diferem entre si pelo teste de Tukey, a 5\% de probabilidade; Para cada profundidade e independente da época, médias seguidas das mesmas letras minúsculas não diferem entre si pelo teste de Tukey, a 5\% de probabilidade; RP: Resistência do solo à penetração; $\theta$ : umidade volumétrica do solo (média de 6 repetições)

Em setembro/2002, na profundidade de 20 -30 cm, independente do teor de umidade no solo, todos os tratamentos sob ação antrópica apresentaram valores de RP superiores a 2,50 MPa, considerados limitantes para o desenvolvimento adequado das plantas cultivadas (Tabela 2), (Camargo \& Alleoni, 1997; Torres \& Saraiva, 2001). Ressalta-se, entretanto, que, como o solo se encontra com umidade próxima do ponto de murcha permanente (Tabela 3) provavelmente não seja este o momento mais propício para análise interpretativa da resistência do solo à penetração de raízes com base na resistência à haste metálica, pelo fato do fluxo de água, nesse instante, não mais atender, satisfatoriamente, à demanda evapotranspirativa da maioria das plantas cultivadas.

Com a umidade próximo à capacidade de campo (janeiro/2003) a resistência do solo à penetração, na profundidade de 20-30 caiu para, no máximo, 2,32 MPa (Tabela 2 e Tabela 3), sendo este não restritivo ao melhor desenvolvimento da maioria das plantas cultivadas (Camargo \& Alleoni, 1997); tal discrepância entre os valores de resistência à penetração, encontrada para solo úmido e seco, confirma a necessidade de se analisar conjuntamente a umidade do solo no momento da realização do teste de penetrometria.

Ainda se analisando a Tabela 2, observa-se um comportamento de tendência de todos os tratamentos se igualarem, em termos de resistência à penetração, para a umidade do solo próximo da capacidade de campo (Tabela 2 e Tabela 3), especialmente na profundidade de $0-5 \mathrm{~cm}$, sugerindo que, talvez, este não deva ser o único momento para se diagnosticar possíveis valores limitantes ao crescimento radicular das plantas, conforme vem sendo estabelecido (Imhoff et al., 2000; Tormena et al., 2004; Beutler et al., 2004).

Já se salientou que, em baixas umidades, provavelmente também não seja o melhor momento de realização desse teste, visto que o déficit hídrico já seria um limitador ao melhor 
desenvolvimento das plantas, independente da restrição física; justifica-se o trabalho de se procurar conhecer o comportamento da resistência à penetração, em função da amplitude da umidade do solo, a fim de otimizar o uso desta ferramenta no diagnóstico da compactação do solo.

Tabela 3. Atributos físico-hídricos do Latossolo vermelho da Microrregião de Goiânia, GO ${ }^{(1)}$

\begin{tabular}{|c|c|c|c|c|c|c|}
\hline \multirow{3}{*}{ Uso } & \multirow{3}{*}{$\begin{array}{c}\text { Ds } \\
\left(\mathrm{kg} \mathrm{dm}^{-3}\right)\end{array}$} & \multicolumn{3}{|c|}{ Porosidade } & \multicolumn{2}{|c|}{ Retenção da água } \\
\hline & & VTP & Macro & Micro & CC & PMP \\
\hline & & \multicolumn{5}{|c|}{$\left(\mathrm{dm}^{3} \mathrm{dm}^{-3}\right)$} \\
\hline \multicolumn{7}{|c|}{ Profundidade de 0 a $5 \mathrm{~cm}$} \\
\hline Mata & $0,95 \mathrm{E}$ & $0,66 \mathrm{~A}$ & $0,34 \mathrm{~A}$ & $0,32 \mathrm{~B}$ & $0,32 \mathrm{~B}$ & $0,17 \mathrm{D}$ \\
\hline Barreirão & $1,22 \mathrm{C}$ & $0,56 \mathrm{C}$ & $0,13 \mathrm{CD}$ & $0,43 \mathrm{~A}$ & $0,43 \mathrm{~A}$ & $0,22 \mathrm{BC}$ \\
\hline PD & $1,34 \mathrm{~B}$ & $0,52 \mathrm{C}$ & $0,13 \mathrm{CD}$ & $0,38 \mathrm{AB}$ & $0,38 \mathrm{AB}$ & $0,24 A B$ \\
\hline Touceira & $1,38 \mathrm{~B}$ & $0,50 \mathrm{D}$ & $0,10 \mathrm{D}$ & $0,40 \mathrm{AB}$ & $0,40 \mathrm{AB}$ & $0,25 A B$ \\
\hline Entre touceiras & $1,47 \mathrm{~A}$ & $0,47 \mathrm{D}$ & $0,05 \mathrm{D}$ & $0,41 \mathrm{AB}$ & $0,41 \mathrm{AB}$ & $0,26 \mathrm{~A}$ \\
\hline Pivô & $1,46 \mathrm{~A}$ & $0,47 \mathrm{D}$ & $0,08 \mathrm{D}$ & $0,39 \mathrm{AB}$ & $0,41 \mathrm{AB}$ & $0,26 \mathrm{~A}$ \\
\hline \multicolumn{7}{|c|}{ Profundidade de 20 a $30 \mathrm{~cm}$} \\
\hline Mata & $1,11 \mathrm{D}$ & $0,60 \mathrm{~B}$ & $0,29 A B$ & $0,31 \mathrm{C}$ & $0,31 \mathrm{C}$ & $0,20 \mathrm{C}$ \\
\hline Barreirão & $1,10 \mathrm{D}$ & $0,61 \mathrm{~B}$ & $0,27 \mathrm{~B}$ & $0,33 \mathrm{BC}$ & $0,33 \mathrm{BC}$ & $0,20 \mathrm{C}$ \\
\hline PD & $1,39 \mathrm{AB}$ & $0,50 \mathrm{CD}$ & $0,13 \mathrm{CD}$ & $0,38 \mathrm{AB}$ & $0,38 \mathrm{AB}$ & $0,25 \mathrm{~A}$ \\
\hline Touceira & $1,29 \mathrm{BC}$ & $0,53 \mathrm{CD}$ & $0,16 \mathrm{C}$ & $0,37 \mathrm{~B}$ & $0,37 \mathrm{~B}$ & $0,23 \mathrm{~B}$ \\
\hline Entre touceiras & $1,30 \mathrm{~B}$ & $0,52 \mathrm{CD}$ & $0,15 \mathrm{CD}$ & $0,38 \mathrm{AB}$ & $0,38 \mathrm{AB}$ & $0,23 \mathrm{~B}$ \\
\hline Pivô & $1,46 \mathrm{~A}$ & $0,47 \mathrm{D}$ & $0,08 \mathrm{D}$ & $0,39 A B$ & $0,41 \mathrm{AB}$ & $0,26 \mathrm{~A}$ \\
\hline
\end{tabular}

Para a profundidade de $0-5 \mathrm{~cm}$, o solo sob mata apresentou os menores valores de Ds e de microporosidade e os maiores valores de VTP e macroporosidade (Tabela 3). Nesta mesma profundidade, todas as áreas que sofreram ação antrópica apresentaram alguma alteração da estrutura do solo (Tabela 3); ainda na profundidade de $0-5 \mathrm{~cm}$, o solo sob pivô central (Pivô) e sob pastejo rotacionado entre touceiras (Entre touceiras) mostrou os maiores valores de Ds e os menores valores de macroporosidade, idênticos estatisticamente (Tabela 3); isto se deve ao fato de que, nas áreas irrigadas, na busca de se otimizar o uso do solo e dos equipamentos de irrigação se cultivam até três safras por ano não se observando, geralmente, as condições ideais de umidade no solo por ocasião do manejo (Oliveira et al., 2003).

Para o solo sob pastejo rotacionado e devido à intensificação dos processos de produção de carne e leite, a elevação da taxa de lotação dos piquetes pode ser uma provável causa desta degradação. Se por um lado a disponibilidade de forragem pode ser inicialmente, suficiente para atender a um número maior de unidade animal por hectare, o pisoteio excessivo resulta no processo de degradação estrutural.

Na profundidade de $20-30 \mathrm{~cm}$, o solo sob mata e sob o Sistema Barreirão (Barreirão) apresentou valores de Ds estatisticamente iguais (Tabela 3) mostrando, assim, a possibilidade de se realizar um manejo adequado da pastagem, respeitando-se fatores fitotécnicos, zootécnicos e edáficos, garantindo a sustentabilidade.

Ao contrário da profundidade superficial, o solo sob pastejo rotacionado na profundidade de $20-30 \mathrm{~cm}$ (Tabela 3) apresentou valores de Ds menores que os encontrados na área sob pivô central (Pivô), independente da região amostrada (Touceira ou Entre touceiras, estatisticamente idênticos nesta profundidade), demonstrando que o impacto do maquinário, principalmente relacionado ao preparo do solo, no solo estudado, se deu em maiores profundidades quando comparado com o pisoteio do gado.

Em relação ao solo sob plantio direto, o alto valor de sua Ds na profundidade de $20-30 \mathrm{~cm}$ (Tabela 3) indica problemas de compactação semelhantes ao que foi observado no solo sob pivô central; considerando-se que isto se deve ao histórico de uso, salienta-se a importância de uma correção física adequada em profundidade antes de se iniciar o sistema de plantio direto.

O solo sob pivô central apresenta, em ambas as profundidades, a maior densidade e macroporosidade abaixo de $0,10 \mathrm{dm}^{3} \mathrm{dm}^{-3}$ (Tabela 3), indicativo de que a aeração já não é mais adequada ao melhor desenvolvimento da maioria das plantas cultivadas (Tormena et al., 2004). A compactação do solo influencia alguns fenômenos importantes que ocorrem no solo, incluindo-se a quantidade de calor, água e gases transportados (Larson et al., 1980) além de, possivelmente, alterar alguns atributos do manejo de irrigação, como quantidade de água disponível (CAD), Irrigação Real Necessária (IRN) e, conseqüentemente, no Turno de Rega (TR).

Segundo Imhoff et al. (2000), além da umidade do solo, a resistência à penetração é influenciada também pela densidade do solo (Ds). Observa-se que em condições de baixa umidade do solo, sua densidade e resistência à penetração se apresentam numa correlação positiva (Figura 1); entretanto, com o aumento da umidade as curvas que representam a relação entre resistência à penetração e densidade do solo, se mostram menos inclinadas, com tendência da resistência a penetração

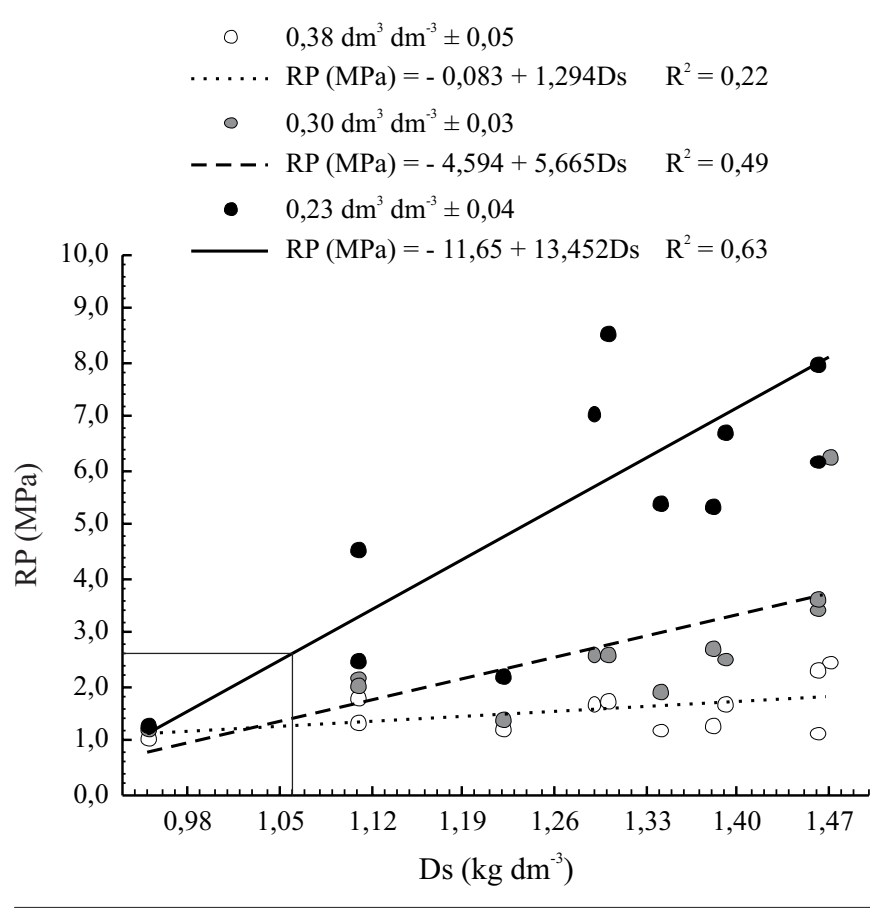

Figura 1. Resistência do solo à penetração (RP), em função da densidade do solo (Ds) em três diferentes umidades do solo $(\theta)$, no Latossolo Vermelho da Microrregião de Goiânia, GO. 
se tornar constante, independente do adensamento do solo, quando sua umidade do solo se aproxima da sua capacidade de campo (Figura 1 e Tabela 3) demonstrando, mais uma vez, o significado da quantificação da umidade do solo por ocasião do diagnóstico da resistência à penetração.

Com o solo com a umidade média em $0,38 \mathrm{dm}^{3} \mathrm{dm}^{-3} \pm 0,05$ (próximo da capacidade de campo), até a densidade estudada (Ds $=1,47 \mathrm{~kg} \mathrm{dm}^{-3}$ ) o solo não apresentou valores de RP acima de 2,5 MPa (Figura 1), considerado crítico para a maioria das plantas cultivadas (Camargo \& Alleoni, 1997); por outro lado, encontrando-se o solo com umidade média de $0,23 \mathrm{dm}^{3} \mathrm{dm}^{-3} \pm 0,04$ (próximo do ponto de murcha permanente; Tabela 3 ) este valor crítico de RP se dará a partir da densidade de $1,06 \mathrm{~kg} \mathrm{dm}^{-3}$, o que indicaria, sem dúvida, uma limitação física para a maioria das plantas cultivadas em qualquer um dos sistemas de uso com ação antrópica, estudados (Tabela 1).

Stone et al. (2002) analisando a influência da compactação na cultura do feijoeiro, cultivado em um Latossolo Vermelho da Microrregião de Goiânia notaram, ao manter o solo com umidade próximo da capacidade de campo, que, para sua densidade de $1,40 \mathrm{~kg} \mathrm{dm}^{-3}$, a resistência à penetração do solo foi de apenas $1,70 \mathrm{MPa}$, atingindo o valor considerado limitante de 6,1 MPa, quando a densidade do solo foi de $1,60 \mathrm{~kg} \mathrm{dm}^{-3}$; este fato, aliado à análise do parágrafo anterior, reforça a hipótese de que o teste de penetrometria não deve ser realizado apenas em um momento específico e, sim, em várias situações, quando o solo se encontrar com diferentes umidades entre a sua capacidade de campo e o ponto de murcha permanente.

Ao se levar em consideração a macroporosidade considerada limitante ao melhor desenvolvimento da maioria das plantas cultivadas como sendo de $0,10 \mathrm{dm}^{3} \mathrm{dm}^{-3}$ (Erickson, 1982; Tormena et al., 2004), vê-se (Figura 2) que valores médios de densidade do solo acima de $1,40 \mathrm{~kg} \mathrm{dm}^{-3}$ limitariam o melhor desenvolvimento das plantas, corroborando com Torres \& Saraiva (2001), que encontraram valores próximos em solo semelhante, do norte do Paraná, e com Arshad et al. (1996) que consideram este valor crítico nos solos argilosos.

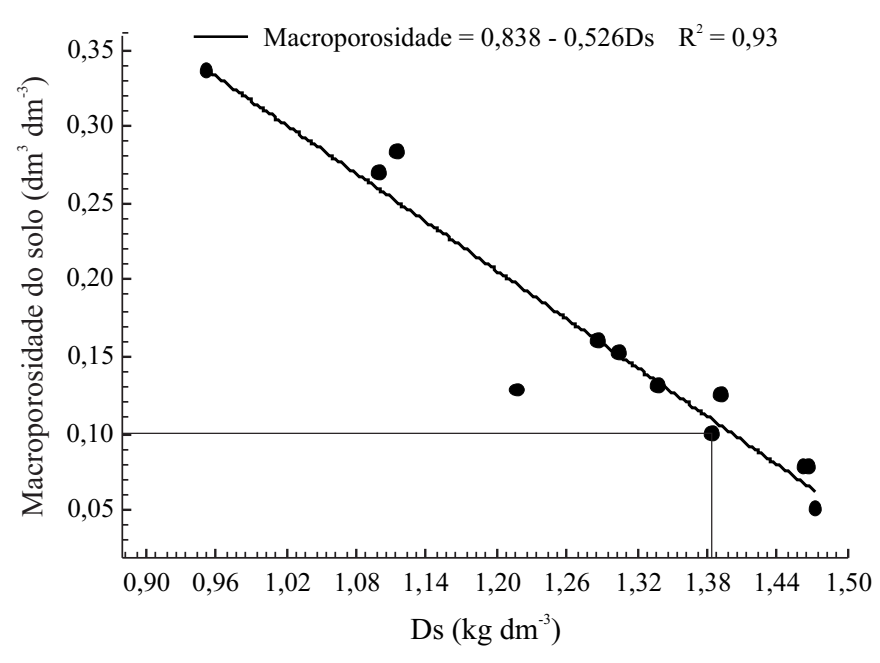

Figura 2. Macroporosidade do solo em função da densidade do solo (Ds) do Latossolo Vermelho da Microrregião de Goiânia, GO

\section{CONCLUSÕES}

1 A avaliação conjunta da resistência à penetração, densidade e umidade do solo indica que o Latossolo em estudo pode apresentar algum tipo de restrição ao melhor desenvolvimento das culturas, quando se encontrar em baixas condições de umidade, em áreas sob manejo.

2. Na área sob Pivô Central seria necessário a manutenção do solo próximo da sua capacidade de campo para que não houvesse restrição mecânica ao desenvolvimento das raízes.

\section{LITERATURA CITADA}

Arshad, M. A.; Lowery, B.; Grossman, R. Physical tests for monitoring soil quality. In: Doran, J. W.; Jones, A. J. (ed.). Methods for assessing soil quality. Madison: Soil Science Society of America, 1996. (SSSA Special Publication, 49)

Beutler, A. N.; Centurion, J. F.; Silva A. P.; Roque, C. G.; Ferraz, M. V. Compactação do solo e intervalo hídrico ótimo na produtividade de arroz de sequeiro. Pesquisa Agropecuária Brasileira, Brasília, v.39, n.6, p.575-580, 2004.

Camargo, O. A.; Alleoni, L. R. F. Compactação do solo e o desenvolvimento de plantas. Piracicaba: ESALQ, 1997. 132p.

Centeno, A. J. Curso de estatística aplicada à biologia. 2.ed., Goiânia: UFG, 2001. 234p.

EMBRAPA - Empresa Brasileira de Pesquisa Agropecuária. Centro Nacional de Pesquisa de Solos. Manual de métodos de análises de solo. 2.ed. Rio de janeiro: Embrapa -CNPS, 1997. 212p.

EMBRAPA - Empresa Brasileira de Pesquisa Agropecuária. Centro Nacional de Pesquisa de Solos. Sistema brasileiro de classificação de solos. Rio de janeiro: Embrapa - CNPS, 1999. 412p.

Erickson, A. E. Tillage effects on soil aeration. In: Predicting tillage effects on soil physical properties and process. Proceedings. Madison: America Society of Agronomy, 1982. p.91-104.

Imhoff, S.; Silva, A. P.; Tormena, C. A. Aplicações de curva de resistência no controle da qualidade física de um solo sob pastagem. Pesquisa Agropecuária Brasileira, Brasília, v.35, n.7, p.1493-1500, 2000.

Kluthcouski, J.; Pacheco, A. R.; Teixeira, S. M.; Oliveira, E. T. Renovação de Pastagens de cerrado com arroz. I. Sistema Barreirão. Goiânia: Embrapa - CNPAF, 1991. 20p. Documento 33.

Larson, W. E.; Gupta, S. C.; Useche, R. A. Compression of agricultural soils from eight soil orders. Soil Science Society of American Journal, Madison, v.44, p.450-457, 1980.

Lopes, L. M.; Oliveira, G. C.; Leandro, W. M. Reconhecimento geopedológico do Campus II e entorno de Goiânia In. Congresso Brasileiro de Ciência do Solo, 24, 1997, Rio de Janeiro. Resumos ... Viçosa: SBCS, 1997. p.363.

Magalhães, R. T.; Kliemann, H. J.; Oliveira, I. P. Evolução das propriedade físicas de solos submetidos ao manejo do Sistema Barreirão. Pesquisa Agropecuária Tropical, Goiânia, v.31, n.1, p.7-13, 2001.

Oliveira, G. C.; Dias Jr., M. S.; Resck, D. V. S.; Curi, N. Alterações estruturais e comportamento compressivo de um Latossolo Vermelho distrófico argiloso sob diferentes sistemas de uso e manejo. Pesquisa Agropecuária Brasileira, Brasília, v.38, n.2, p.291-299, 2003.

R. Bras. Eng. Agríc. Ambiental, v.11, n.3, p.265-270, 2007. 
Oliveira, L. B. Determinação da macro e microporosidade pela mesa de tensão em amostras de solo com estrutura indeformada. Pesquisa Agropecuária Brasileira, Brasília, v.3, p.197-200, 1968.

Phene, C. J.; Beale, O. W. High-frequency irrigation for water nutrient management in humid regions. Soil Science of America Jounal, Madison, v.40, p.430-436, 1972.

Ribon, A. A.; Tavares Filho, J. Models for the estimation of the physical quality of a Yellow Red Latosol (Oxisol) under pasture. Brazilian Archives of Biology and Technology, Londrina, v.47, n.1, p.25-31, 2004.

Sano, E.; Dambrós, L.; Oliveira, G. C. Diagnóstico geopedológico, uso da terra e vulnerabilidade ambiental no estado de Goiás. Agência Ambiental, Goiânia, 2004. CD-Rom (Relatório Técnico).

SEPLAN/AGIM. Sistema de informações geográficas do estado de Goiás. Mapa de solos do estado de Goiás. Goiânia. 2002, CD-Rom.

Stolf, R. Teoria e teste experimental de fórmulas de transformação dos dados de penetrômetros de impacto em resistência do solo. Revista Brasileira de Ciência do Solo, Campinas, v.15, n.3, p.229-235, 1991.
Stolf, R.; Fernandes, J.; Furlani Neto, V. L. Penetrômetro de impacto modelo IAA/Planalsucar-Stolf: Recomendação para seu uso. STAB, Piracicaba, v.1, n.3, p.18-23, 1983.

Stone, L. F.; Guimarães, C. M.; Moreira, J. A. A. Compactação do solo na cultura do feijoeiro. I: Efeitos nas propriedades físico-hídricas do solo. Revista Brasileira de Engenharia Agrícola e Ambiental, Campina Grande, v.6, n.2, p.207-212, 2002.

Teixeira Neto, M. L. Efeito de espécies vegetais para cobertura no sistema plantio direto na Região dos Cerrados sobre as propriedades do solo. Goiânia: UFG, 2002. 151p. Dissertação Mestrado

Tormena, C. A.; Friedrich, R.; Pintro, J. C.; Costa, A. C. S.; Fidalski, J. Propriedades físicas e taxa de estratificação de carbono orgânico num Latossolo Vermelho após dez anos sob dois sistemas de manejo. Revista Brasileira de Ciência do Solo. Viçosa, v.28, n.6, p.1023-1031, 2004.

Torres, E.; Saraiva, O. F. Camadas de impedimento mecânico do solo em sistemas agrícolas com soja. Londrina: Embrapa CNPSO, 2001. 58p. 